\title{
The difficult patient: drug interaction and the influence of concomitant diseases on the treatment of hypothyroidism
}

\author{
O paciente difícil: interação entre drogas e influência de \\ doenças concomitantes no tratamento do hipotiroidismo
}

Laura S. Ward'

\section{SUMMARY}

Although most hypothyroid patients do well with one single tablet of thyroxine daily, approximately $10 \%$ are dissatisfied and another important group of patients is difficult to control. We reviewed the most common causes for frequent-dose adjustment or high-dose requirement, including poor compliance with therapy and inadequate medication. Since these two causes have been ruled out, drug interaction and other concomitant diseases need to be investigated. Requirements of thyroxine increase in all conditions characterized by impaired gastric acid secretion. Proton-pump inhibitors, antacids and a long list of drugs may decrease thyroxine absorption. In addition, a series of diseases including celiac disease and chronic inflammatory intestinal diseases, as well as nutritional habits may be important in patient control. Finally, we mention the effects of a growing list of drugs and thyroid disruptors that may also affect thyroid hormone metabolism at many levels. Arq Bras Endocrinol Metab. 2010;54(5):435-42

\section{Keywords}

Medication-taking behavior; compliance; bioequivalence; absorption; nutritional habits

\section{SUMÁRIO}

Embora a maior parte dos pacientes com hipotiroidismo fique bem com um único comprimido diário de tiroxina, aproximadamente $10 \%$ não ficam satisfeitos e outro importante grupo de pacientes apresenta controle difícil. Foram revistas as causas mais comuns para necessidades frequentes de ajuste de dose ou uso de dose elevadas, incluindo falta de adesão à terapia e medicação inadequada. Descartando-se essas duas causas, é necessário investigar o uso de drogas e a presença de doenças concomitantes. Existe necessidade maior de tiroxina quando diminui a secreção ácida do estômago. Inibidores de bomba de prótons, antiácidos e uma longa lista de drogas podem dificultar a absorção da tiroxina. Várias doenças, incluindo a doença celíaca e as doenças intestinais inflamatórias crônicas, além dos hábitos alimentares, são importantes no controle do paciente hipotiroideo. Finalmente, foram mencionados os efeitos de uma lista crescente de drogas e disruptores que podem afetar o metabolismo tiroidiano em diferentes níveis. Arq Bras Endocrinol Metab. 2010;54(5):435-42

\section{Descritores}

Comportamento; adesão; bioequivalência; absorção; hábitos alimentares
${ }^{1}$ Faculdade de Ciências Médicas, Universidade Estadual de Campinas (FCM-Unicamp), Campinas, SP, Brazil

\section{Correspondence to:}

Laura S. Ward

Laboratório de Genética Molecular do Câncer, Faculdade de Ciências Médicas, Universidade Estadual de Campinas

Rua Tessalia Vieira de Camargo, 126 13083-970 - Campinas, SP, Brazil ward@fcm.unicamp.br

Received on Mar/17/2010 Accepted on Apr/10/2010

\section{INTRODUCTION}

$\mathrm{T}$ hyroid hormone therapy is often rewarding, simple and inexpensive. Most patients are satisfied with one single tablet of synthetically derived levothyroxine daily. Once the dosage has been adjusted to give opti- mal clinical response and normal serum TSH, the replacement dosage often remains stable for years. However, nearly $10 \%$ of the patients are not satisfied and another important part of our patients is not well controlled and needs unusually high doses of thyroid hormone replacement (1). Why would this happen? 
A series of recent publications have been pointing to genetic polymorphisms in deiodinases and thyroid hormone transporters as the main causes of dissatisfaction. Common germline genetic variations are probably responsible for the relatively wide range of serum thyroid hormone levels observed in the normal population and may also be involved in the differential bioavailability of thyroid hormones in different tissues (2). However, this review does not focus on the dissatisfied patient, but on the patient who is difficult to control.

\section{COMPLIANCE WITH THERAPY AND MEDICATION- TAKING BEHAVIOR}

The causes for frequent-dose adjustment or highdose requirement are, in general, prosaic. The most common cause is poor compliance with therapy and medication-taking behavior. This issue is relevant for the management of all chronic asymptomatic or oligosymptomatic diseases, such as diabetes, hypertension and other diseases in which no immediate physical symptoms result from such behavior (3). One day's tablet represents $24 \%$ of the weekly dose and, because of the long half-life of thyroxine, the influence of missing a day on thyroid hormones and TSH levels will manifest over several days. A recent publication involving a large number of Canadian elders who had received a new prescription for an antihypertensive agent demonstrated that persistence at 1 year dropped $50-60 \%$ (4). The authors found that compliance was greater in women, patients of higher socioeconomic status, and younger individuals, with lower burdens of comorbidities (4). Unfortunately, most of our patients do not fulfill this profile.

Confirming other data on the subject, we published a compliance study comprising 100 patients from public hospitals in Campinas and Rio de Janeiro, who presented persistently elevated TSH levels despite increasing the levothyroxine dose (5). Our poor compliance rate was similar to that seen in literature: $82 \%$ of the patients. Sixty two percent of the patients had a poor medication-taking behavior mostly because they forgot or neglected to take their pills, but $12 \%$ of these patients complained about intolerance or side effects and $8 \%$ claimed they could not afford to buy the medication (5). Levothyroxine is allegedly supplied at our primary care institutions, but unfortunately this supply is not regular. Subsequently, we supplied one of the four preparations containing levothyroxine commer- cially available at that time, reinforced the importance of the medication by giving lectures to the patients, and undertook a simple pill counting control compliance measure. All patients were controlled after one month with all four preparations; however, the most important finding of our trial was that $18 \%$ of these patients, after just one month of adequate medication-taking, were hyperthyroid. Indicating they had already been prescribed a levothyroxine dosage higher than they were really in need of. And, certainly, the fact that they became hyperthyroid when they started to take their pills appropriately represents a risk. None of our patients had any cardiac symptom or complained of any problem, but they could have had serious problems especially considering that most of these patients were elderly and presented comorbidities.

Excluding poor medication-taking behavior is usually a difficult task. After exhausting every usual measure for compliance such as pill counting, counseling methods, motivational interviewing and problem solving treatment, a clinical test to estimate levothyroxine absorption may be proposed. The test consists of a single large dose of thyroxine administration, usually $1,000 \mathrm{mcg}$, and then monitoring serum T4 levels over time (6). Unfortunately, there are no well-established standards for this test. Even though it indicates that the patient absorbs thyroxine when exposed to a large dose, it does not rule out impairment of normal dose absorption. Moreover, the test does not quantify the absorption impairment caused by the edema produced by the hypothyroidism on the small bowel mucosa. Hence, simply increasing the levothyroxine dose may have the same practical effect of submitting the patient to the single dose test, with the advantage of treating him.

\section{ADEQUACY OF MEDICATION}

Once poor-medication is discarded and before considering drug interaction and concomitant diseases, it is necessary to check if the patient medication is adequate. It is important to remember that certain conditions may physiologically require higher doses of thyroid hormone replacement, such as pregnancy or childhood (Table 1).

Obesity may also be a cause of a higher levothyroxine requirement. In fact, individual levothyroxine requirements are more related to the lean body mass than to the total body weight (7). On studying more than 27 thousand Norwegians without previously known 
Table 1. Causes of high-dose thyroid hormone replacement

Poor medication-taking behavior/compliance

Adequacy of medication: pregnancy, infancy/adolescence, obesity

Drug interaction

Concomitant diseases

Type 2 deiodinase polymorphisms/ thyroid hormone transporters

thyroid disease, Asvold and cols. (8) proved that low thyroid function was associated with high body mass for men and women (8). Two hypotheses have been proposed to explain the relation of thyroid function with body mass. The first one involves the effect of leptin and other adipokines (9), which is favored by the following facts: weight reduction in obese individuals may be associated with reduced thyroid function $(10,11)$, and patients with anorexia nervosa who gain weight have increased thyroid function (12). The second hypothesis suggests that low thyroid function may lead to obesity, probably reducing basal metabolic rate (13).

Requirement also seems to be associated with hormonal status. Studying 50 patients after thyroidectomy, Jackeline Jonklaas (14) found that the weight-based levothyroxine dosage required to normalize TSH was $1.7 \mathrm{mcg} / \mathrm{kg}$ in both sexes; however, premenopausal women appeared to have a greater dosage requirement than both postmenopausal women and men (14). Of course, dose requirements are also age-dependent, possibly because of the combination of weight loss, lean mass loss and decreased clearance of T4 $(14,15)$.

Another very common problem is that the patient may be using an inadequate preparation or a preparation with no bioequivalence. Levothyroxine is a narrow therapeutic range drug for which precise and consistent dosing are essential, particularly in the elderly and in high-risk thyroid cancer patient treatment. It is not unusual to see patients using "natural medicines" that do not contain appropriate doses of the active principals, formulas or manipulated preparations that lack a proper control. There are different brand-name and generic levothyroxine products being manufactured in Brazil and many patients switch from one to another at their convenience or at the pharmacist's or relatives' advice, frequently without the prescribing physician's knowledge. Generic levothyroxine is considered equivalent to the brand names and, because there is a cost differential between generic levothyroxine and many of the brand name products, physicians and patients have been turning to generic levothyroxine. However, the- re is considerable concern on the bioequivalence standards for levothyroxine product comparisons (9) and the American Thyroid Association (ATA), along with the American Association of Clinical Endocrinologists (AACE), and The Endocrine Society (TES) have endorsed a joint statement expressing concern about the flawed methodology used to determine bioequivalence and the potential harm it could bring to patients (16). In fact, there have been a series of adverse event reports (17). Patients should be alerted that they will be required to perform additional blood tests and dose adjustments after switching preparations.

\section{DRUG INTERACTION AND CONCOMITANT DISEASES}

If the patient was correctly diagnosed, poor medication-taking or compliance issues were discarded, and the dose prescribed is adequate, you may be facing a drug interaction problem or a concomitant disease that impairs levothyroxine's proper absorption or action (Table 2).

Table 2. Causes of impaired levothyroxine absorption

\begin{tabular}{ll}
\hline Drugs & \\
\hline Proton-pump inhibitors (PPI) & Calcium salts \\
Aluminium, magnesium hydroxide & Calcium carbonate \\
Sucralfate & Orlistat \\
Ion exchange resins & Cation exchange resins \\
Ferrous sulfate & Bile acid sequestrants \\
& (Cholestyramine; Colestipol) \\
\hline Diseases & \\
\hline Helicobacter pylori infection & Celiac disease \\
Atrophic gastritis & Short bowel syndrome \\
Giardiasis and other parasitic diseases & Lactose intolerance \\
Other intestinal chronic inflammatory diseases \\
\hline Nutritional habits & \\
\hline Coffee & Juice \\
Cereals & Other foods \\
\hline
\end{tabular}

The absorption of levothyroxine occurs within an interval of 3 hrs of ingestion, mainly in the jejunum and ileum (18-20). On average, approximately $70 \%-80 \%$ of the available tablet dose is absorbed by the euthyroid individual, and this absorption rate may diminish in the hypothyroid patient (18). Absorption is maximal when the stomach is empty, reflecting the importance of gastric acidity in the process $(21,22)$. In fact, the comple- 
xity of the acid producing machinery in the stomach may contribute to the individual variability observed in daily thyroxine requirement in a longitudinal evaluation (23).

There is an increase in the requirement of oral thyroxine in all conditions characterized by impaired gastric acid secretion, which is more pronounced in adult patients presenting with atrophic gastritis and concomitant $H$. pylori infection, who have severe hypochlorhydria (24). In an attempt to reduce the size of their goiters or at least to minimize further growth, Centanni and cols. (21) treated 248 multinodular goiter patients with levothyroxine (21). The dose was progressively increased until a low serum thyrotropin level (0.05 to $0.20 \mathrm{mU}$ per liter) was reached. There were 113 patients with multinodular goiter and impaired gastric acid secretion. Fifty-three had $H$. pylori-related nonatrophic gastritis and 60 patients had atrophic gastritis. The authors observed that patients with atrophic gastritis required an increase of $27 \%$ in the thyroxine dose, whereas patients with $H$. Pylori non-atrophic gastritis required an increase of $22 \%$ in their dose. Interestingly, there was an additive effect: patients with both H. pylori and atrophic gastritis needed a $34 \%$ higher dose of T4. Although the clinical importance of these findings is fairly clear, the mechanism by which intestinal absorption of thyroxine is impaired in patients with hypochlorhydria is unknown. We may only speculate that oral thyroxine is administered as sodium salt, which is less lipophilic than the native hormone, which enters target cells both through passive diffusion and in a carrier-mediated, inhibitable way $(25,26)$. In this respect, achlorhydria due to atrophic gastritis $(27,28)$ and ammonia production, or both, which are characteristic of $H$. pylori infection $(29,30)$ may alter the ionization status and the conformational characteristics of the thyroxine molecule and thus, the efficiency of intestinal absorption of the hormone.

It is important to remember that atrophic gastritis and serum parietal-cell antibodies are associated with Hashimoto's disease and serum thyroid peroxidase antibodies. Therefore, patients with Hashimoto's disease are more susceptible to present a concomitant autoimmune atrophic gastritis. And, of course, many individuals with atrophic gastritis and parietal-cell antibodies also present $H$. pylori infection (21).

Among the 248 multinodular goiter patients treated with thyroxine by Centanni and cols. (21), there were 11 patients diagnosed with $H$. pylori who were treated for this infection. TSH levels measured before and after $H$. pylori eradication demonstrated a clear effect of gastric infection on the absorption of thyroxine impairment, an effect that has been proved by others too $(21,31)$. In $H$. pylori infection, bacterial production of urease neutralizes gastric $\mathrm{pH}$, impairing the absorption of many drugs (31). Other 10 patients with multinodular goiter and gastroesophageal reflux disease, who were treated with both thyroxine and omeprazole, had their serum thyrotropin levels evaluated before and after treatment. Omeprazole has also got an important effect per se, probably because it causes hypochlorhydria, likewise all proton-pump inhibitors (PPI) do $(21,32)$. In conclusion, $H$. pylori infection and hypochlorhydria should be considered when prescribing any drugs for which absorption is potentially affected by intragastric $\mathrm{pH}$.

In addition to PPI, antacids also impair levothyroxine absorption. There are other commonly used drugs that impair intestinal absorption such as ion exchange resins, bile acid sequestrants, and sucralfate, which have the same effect. Ferrous sulfate, frequently used to treat anemia, may impair thyroxine as well as orlistat absorption, a drug that works by interfering with the action of gastrointestinal (GI) lipase in the GI tract, and calcium (33). There is an increasing number of drugs that have been reported to affect levothyroxine absorption (33) (Table 2).

Furthermore, a series of other diseases can impair levothyroxine absorption as well. Celiac disease is worth the mention. In fact, likewise atrophic body gastritis, celiac disease and other autoimmune conditions, including inflammatory small bowel disease, are frequently associated with autoimmune thyroiditis $(34,35)$, which in turn consists in the main cause of hypothyroidism in adult patients (36). Celiac disease may have mild or subtle symptoms, and there is a case report in which resistant hypothyroidism appeared to be the only major manifestation of the disease (37). The patient improved after a gluten-free diet was introduced (37).

Bariatric surgery and all surgeries that reduce gastrointestinal absorption surface may also impair thyroxine absorption (38). It is especially relevant to remember that certain parasitic diseases may be an important cause of malabsorption in underdeveloped countries. There is a report of a severe case of hypothyroidism reputed to have been caused by an intestinal giardiasis (39). Other causes of malabsorption may include lactose intolerance $(40)$. 
Cardiovascular diseases deserve a special consideration concerning thyroid hormone administration. We all fear the potential detrimental effects of thyroid hormone administration in a variety of clinical settings. Indeed, high doses of thyroxine can cause cardiac ischemia, even in the absence of significant coronary artery disease; increase oxygen demand, coronary spasm and arrhythmias (41). For this reason, levothyroxine is introduced in very small doses, in general, half of the $25 \mathrm{mcg}$ tablet in patients with cardiovascular diseases. Increases in dosage are also made very cautiously and slowly and, many times, we are tempted to maintain the patient in a state of subclinical hypothyroidism. However, experimental data suggest that thyroid hormones improve myocardial functions, increase capillary flow and induce angiogenesis after myocardial infarction (42-48). In fact, thyroid hormone administration shows inotropic and antiarrhythmic properties and reduces the risk of death after and some clinical conditions such as chronic congestive heart failure (42), organ transplantation $(43,44)$, coronary artery (45) and cardiopulmonary bypass (46), myocardial ischemia (47) and in prolonged critical illness (48). Consequently, it is important to always aim at a target TSH in the normal range for the patient's age, especially if the patient has a cardiovascular disease. Also, it is important to remember that congestive heart failure is associated to altered morphology, permeability, and absorption of the digestive tract (49).

\section{NUTRITIONAL HABITS}

Nutritional habits are also very important to control hypothyroid patients (Table 2). Most of the active components of a thyroxine pill are absorbed within the first 20-30 minutes after ingestion, although completion of absorption takes three hours. Therefore, it is recommended to obey a 30 -minute interval between thyroxine pill ingestion and breakfast. A series of reports have demonstrated that coffee, especially espresso coffee, impairs thyroxine absorption (50). Dietary fibers appear to have a smaller, but still significant effect on thyroxine absorption (51). Grapefruit juice and probably other citric fruits might also impair thyroxine absorption (52).

\section{OTHER DRUGS THAT INTERACT WITH THYROXINE}

In addition to drugs that cause impairment in thyroxine absorption, there are other drugs that interact with thyroxine. Although they are not the scope of this review, it is worth mentioning that there are drugs that may increase hepatic metabolism and cause hypothyroidism (carbamazepine, hydantoins, phenobarbital, rifampin); that may cause a decrease in thyroid hormone secretion and, therefore, cause a higher dose requirement of thyroxine (aminoglutethimide, amiodarone, iodide-including and iodine-containing radiographic contrast agents, lithium, methimazole, propylthiouracil, sulfonamides, tolbutamide); that may decrease T4 5'-deiodinase activity (amiodarone, beta-adrenergic antagonists: propranolol $>160 \mathrm{mg} /$ day, glucocorticoids: dexamethasone $\geq 4 \mathrm{mg}$ /day, propylthiouracil); that may increase serum TBG concentration (estrogen, clofibrate, heroin/methadone, mitotane, tamoxifen); that may decrease serum TBG concentration (androgens/anabolic steroids, glucocorticoids, nicotinic acid, asparginase); that may cause protein-binding site displacement (furosemide: $>80 \mathrm{mg} \mathrm{IV}$, heparin, hydantoins, nonsteroidal anti-inflammatory drugs: fenamates, phenylbutazone, salicylates $>2 \mathrm{~g} /$ day). A series of other drugs need attention because, through unknown or complex mechanisms, they may interfere with thyroxine therapy; antidiabetic agents: biguanides, meglitinides, sulfonylureas, thiazolidinediones, insulin; antidepressants: tricyclic (e.g., amitriptyline), tetracyclics (e.g., maprotiline), selective serotonin reuptake inhibitors (SSRIs; e.g., sertraline); growth hormones: somatrem, somatropin; oral anticoagulants: coumarin derivatives, indandione derivatives; cytokines: interferon- $\alpha$, interleukin-2; others: ketamine, sympathomimetics, cardiac glycosides, chloral hydrate, diazepam, ethionamide, lovastatin, metoclopramide,6mercaptopurine, nitroprusside, para-aminosalicylate sodium, perphenazine, resorcinol (excessive topical use), thiazide diuretics.

Interestingly, some agents, such as amiodarone and iodide may cause both hypo- and hyperthyroidism $(53,54)$. Amiodarone is a drug very frequently used in Brazil. We have a 10-million Chagas disease population and amiodarone is a very potent and effective antiarrhythmic drug. It is a benzofuran-derived, iodine-rich compound with some structural similarity to thyroxine (T4). Amiodarone contains approximately $37 \%$ iodine by weight. Each $200-\mathrm{mg}$ tablet is estimated to contain approximately $75 \mathrm{mg}$ of organic iodide, $8 \%-17 \%$ of which is released as free iodide. Standard maintenance therapy with $200 \mathrm{mg}$ amiodarone can provide more than 100 times the daily iodine requirement. Amioda- 
rone causes a wide spectrum of effects on the thyroid $(53,54)$. In a study of 81 Chagas disease patients using amiodarone, we found that $21 \%$ of the patients had elevated TSH levels and $8 \%$ low TSH levels (55). Amiodarone may also decrease T4 deiodinase activity. Likewise propanolol, dexametasone and PTU may decrease T3 levels. Although usually normal, serum T4 levels may occasionally be slightly increased. In patients treated with large doses of propranolol (> $160 \mathrm{mg} /$ day), T3 and T4 levels change slightly, TSH levels remain normal, and patients are clinically euthyroid. It should be noted that actions of particular beta-adrenergic antagonists may be impaired when the hypothyroid patient is converted to the euthyroid state. Short-term administration of large doses of glucocorticoids may decrease serum T3 concentrations by $30 \%$, with minimal change in serum T4 levels. However, long-term glucocorticoid therapy may result in slightly decreased T3 and T4 levels due to decreased TBG production.

Since many of our hypothyroid patients are also diabetic, we should remember the TSH-lowering effect of metformin (56).

Finally, we need to mention the effects of a growing list of thyroid disruptors that may also affect thyroid hormone metabolism at many levels (57) (Table 3).

An increasing amount of toxic substances has been described, many of which we still do not fully unders- tand how they affect thyroid hormones. For instance, a study of 42 healthy non-smoker petrol filling workers from India found a significant toxic effect on workers exposed for longer duration who presented lower TSH levels. However, whereas their serum T3 levels dropped, T4 and free T4 levels augmented (58). The effects of thyroid disruptors are complex and still difficult to interpret. They may account for a part of the patients who we are convinced that are compliant, adequately medicated and do not present any absorption impairment, but have a hard time controlling their hypothyroidism.

In conclusion, the patient difficult to control most frequently is not compliant or was not adequately diagnosed/prescribed. Indeed, the majority of our patients fit this profile and become adherent to therapy after a few good conversations. In some patients, however, we need to exclude concomitant disease and drug interaction. Eventually, in the rare cases in which all these issues were discarded, we remain with the hypothesis of the presence of thyroid disruptors, deiodinase or thyroid hormone transporter polymorphisms leading to higher dose requirements and we just adjust thyroxine dose. Treating the hypothyroid difficult patient may not be so difficult, after all.

Disclosure: no potential conflict of interest relevant to this article was reported.

Table 3. Thyroid disruptors: clinical effect and putative mechanism. Notice that some products have several toxic effects

\begin{tabular}{lll}
\hline Xenobiotic product & Clinical effect on thyroid metabolism & Putative mechanism \\
\hline Perchlorates, thiyocyanate, nitrate, phthalates, bromates & Decreases synthesis of T3 and T4 & Blocking iodide uptake into thyroid cell \\
$\begin{array}{l}\text { Soy, isoflavones, methimazole, benzophenone } 2 \\
\text { (pesticide), amitrole (pesticide) }\end{array}$ & Decreases synthesis of T3 and T4 & Blocking TP0 production into thyroid cell \\
PCBs, pentachlorophenol, flame retardants, phthalates & $\begin{array}{l}\text { Possible effect on fetal brain T4 production and brain } \\
\text { development }\end{array}$ & Compete to thyroid transport protein \\
Dioxin, PBDE, chlordane (pesticide) & Increase billiary elimination of both T4 and T3 & Alter transport across cell membrane \\
Acetochlor (herbicide) & Increase billiary metabolism of both T4 and T3 & Enhance hepatic metabolism \\
$\begin{array}{l}\text { Triclosan, PCBs, dioxin, difuran, pentachlorophenol } \\
\text { (pesticide) }\end{array}$ & $\begin{array}{l}\text { Decrease sulfation of thyroid hormones and possibly } \\
\text { decrease peripheral T3 synthesis }\end{array}$ & Inhibit sulfation \\
\hline PCBs, octyl methoxycinnamate, FD\&C red dye & Decrease peripheral T3 synthesis & Inhibit deiodinase activity \\
DDT, PCBs & Decrease T3 and T4 production & Inhibit TSH receptor \\
\hline
\end{tabular}

Polychlorinated biphenyls (PCBS) were commonly used as stabilizing additives in the manufacture of flexible PVC coatings for electrical wiring and electronic components to enhance the heat and fire resistance of the PVC.

Perchlorates are used extensively within the pyrotechnics industry, and ammonium perchlorate is also a component of solid rocket fuel.

Thiyocyanate is used as a precursor for the synthesis of pharmaceuticals and other specialty chemicals.

Dioxins are the by-products of various industrial processes (i.e., bleaching paper pulp, and chemical and pesticide manufacture) and combustion activities (i.e., burning household trash, forest fires, and waste incineration).

Bromates are formed many different ways in municipal drinking water.

Phthalates are mainly used as plasticizers (substances added to plastics to increase their flexibility, transparency, durability, and longevity).

Difuran is used in the elaboration and/or manufacturing of flavor and fragrance agents.

Octyl methoxycinnamate is an component used in some sunscreens and lip balms. 


\section{REFERENCES}

1. Saravanan P, Chau WF, Roberts N, Vedhara K, Greenwood R, Dayan CM. Psychological well-being in patients on 'adequate' doses of I-thyroxine: results of a large, controlled community-based questionnaire study. Clin Endocrinol. 2002;57(5):577-85.

2. Dayan CM, Panicker V. Novel insights into thyroid hormones from the study of common genetic variation. Nat Rev Endocrinol. 2009;5(4):211-8.

3. Burnier M. Medication adherence and persistence as the cornerstone of effective antihypertensive therapy. Am J Hypertens. 2006;19(11):1190-6.

4. Friedman O, McAlister FA, Yun L, Campbell NR, Tu K; Canadian Hypertension Education Program Outcomes Research Taskforce. Antihypertensive drug persistence and compliance among newly treated elderly hypertensives in Ontario. Am J Med. 2010;123(2):173-81.

5. Bagattoli RM, Vaisman M, Lima JS, Ward LS. Estudo de adesão ao tratamento do hipotiroidismo. Arq Bras Endocrinol Metab. 2000;44(6):483-7.

6. Morris JC. How do you approach the problem of TSH elevation in a patient on high-dose thyroid hormone replacement? Clin Endocrinol. 2009;70(5):671-3.

7. Santini F, Pinchera A, Marsili A, Ceccarini G, Castagna MG, Valeriano $R$, et al. Lean body mass is a major determinant of levothyroxine dosage in the treatment of thyroid diseases. J Clin Endocrinol Metab. 2005;90(1):124-7.

8. Asvold BO, BjøroT, Vatten LJ. Association of serum TSH with high body mass differs between smokers and never-smokers. J Clin Endocrinol Metab. 2009;94(12):5023-7.

9. Weiss RE, Brown RL. Doctor . . . could it be my thyroid? Arch Intern Med. 2008;168(6):568-9.

10. Kok P, Roelfsema F, Langendonk JG, Frölich M, Burggraaf J, Mein$\operatorname{ders} A E$, et al. High circulating thyrotropin levels in obese women are reduced after body weight loss induced by caloric restriction. J Clin Endocrinol Metab. 2005;90(8):4659-63.

11. Reinehr T, de Sousa G, Andler W. Hyperthyrotropinemia in obese children is reversible after weight loss and is not related to lipids. J Clin Endocrinol Metab. 2006;91(8):3088-91.

12. Onur $S$, Haas V, Bosy-Westphal $A$, Hauer M, Paul T, Nutzinger $D$, $\mathrm{Klein} \mathrm{H}$, et al. L-tri-iodothyronine is a major determinant of resting energy expenditure in underweight patients with anorexia nervosa and during weight gain. Eur J Endocrinol. 2005;152(2):179-84.

13. Knudsen N, Bülow I, Laurberg P, Ovesen L, Perrild H, Jørgensen T. Small differences in thyroid function may be important for body mass index and the occurrence of obesity in the population. $J$ Clin Endocrinol Metab. 2005;90(7):4019-24.

14. Jonklaas J. Sex and age differences in levothyroxine dosage requirement. Endocr Pract. 2010;16(1):71-9.

15. Sawin CT, Herman T, Molitch ME, London MH, Kramer SM. Aging and the thyroid. Decreased requirement for thyroid hormone in older hypothyroid patients. Am J Med. 1983;75(2):206-9.

16. American Thyroid Association; Endocrine Society; American Association of Clinical Endocrinologists. Joint statement on the U.S. Food and Drug Administration's decision regarding bioequivalence of levothyroxine sodium. Thyroid. 2004;14(7):486.

17. Hennessey JV, Malabanan AO, Haugen BR, Levy EG. Adverse Event Reporting in Patients Treated with Levothyroxine: Results of the Pharmacovigilance Task Force Survey of the American Thyroid Association, American Association of Clinical Endocrinologists and The Endocrine Society. Endocr Pract. 2010 Feb 11:1-41. [Epub ahead of print]

18. Read DG, Hays MT, Hershman JM. Absorption of oral thyroxine in hypothyroid and normal man. J Clin Endocrinol Metab. 1970;30(6):798-9.
19. Benvenga S, Bartolone L, Squadrito S, Lo Giudice F, Trimarchi F. Delayed intestinal absorption of levothyroxine. Thyroid. 1995;5(4):249-53.

20. Read DG, Hays MT, Hershman JM. Absorption of oral thyroxine in hypothyroid and normal man. J Clin Endocrinol Metab. 1970;30(6):798-9.

21. Centanni M, Gargano L, Canettieri G, Viceconti N, Franchi A, Delle Fave G, et al. Thyroxine in goiter, Helicobacter pylori infection, and chronic gastritis. N Engl J Med. 2006;354(17):1787-95.

22. Wenzel KW, Kirschsieper HE. Aspects of the absorption of oral L-thyroxine in normal man. Metabolism. 1977;26(1):1-8.

23. Yao X, Forte JG. Cell biology of acid secretion by the parietal cell. Annu Rev Physiol. 2003;65:103-31.

24. Hennemann G, Docter R, Friesema EC, de Jong M, Krenning EP, Visser TJ. Plasma membrane transport of thyroid hormones and its role in thyroid hormone metabolism and bioavailability. Endocr Rev. 2001;22:451-76.

25. Centanni M, Robbins J. Role of sodium in thyroid hormone uptake by rat skeletal muscle. J Clin Invest. 1987;80:1068-72.

26. Annibale B, Marignani M, Azzoni C, D'Ambra G, Caruana P, D'Adda $T$, et al. Atrophic body gastritis: distinct features associated with Helicobacter pylori infection. Helicobacter. 1997;2:57-64.

27. Centanni M, Marignani M, Gargano L, Corleto VD, Casini A, Delle Fave G, et al. Atrophic body gastritis in patients with autoimmune thyroid disease: an underdiagnosed association. Arch Intern Med. 1999;159:1726-30.

28. Kuipers EJ, Uyterlinde AM, Peña AS, Roosendaal R, Pals G, Nelis $\mathrm{GF}$, et al. Long-term sequelae of Helicobacter pylori gastritis. Lancet. 1995;345:1525-8.

29. Sachs G, Shin JM, Munson K, Vagin O, Lambrecht N, Scott DR, et al. Review: the control of gastric acid and Helicobacter pylori eradication. Aliment PharmacolTher. 2000;14:1383-401.

30. Yao X, Forte JG. Cell biology of acid secretion by the parietal cell. Annu Rev Physiol. 2003;65:103-31.

31. Lahner E, Annibale B, Delle Fave G. Systematic review: Helicobacter pylori infection and impaired drug absorption. Aliment Pharmacol Ther. 2009;29(4):379-86.

32. Ananthakrishnan S, Braverman LE, Levin RM, Magnani B, Pearce EN. The effect of famotidine, esomeprazole, and ezetimibe on levothyroxine absorption. Thyroid. 2008;18(5):493-8.

33. Singh N, Weisler SL, Hershman JM. The acute effect of calcium carbonate on the intestinal absorption of levothyroxine. Thyroid. 2001;11(10):967-71.

34. Collin P, Kaukinen K, Välimäki M, Salmi J. Endocrinological disorders and celiac disease. Endocr Rev. 2002;23:464-83.

35. Boelaert K, Newby PR, Simmonds MJ, Holder RL, Carr-Smith JD, Heward JM, et al. Prevalence and relative risk of other autoimmune diseases in subjects with autoimmune thyroid disease. Am J Med. 2010;123(2):183.e1-9.

36. Surks MI, Ortiz E, Daniels GH, Sawin CT, Col NF, Cobin RH, et al. Subclinical thyroid disease. Scientific review and guidelines for diagnosis and management. J Am Med Assoc. 2004;291:228-38.

37. McDermott $\mathrm{JH}$, Coss $\mathrm{A}$, Walsh $\mathrm{CH}$. Celiac disease presenting as resistant hypothyroidism. Thyroid. 2005;15(4):386-8.

38. Padwal R, Brocks D, Sharma AM. A systematic review of drug absorption following bariatric surgery and its theoretical implications. Obes Rev. 2010;11:41-50.

39. Seppel T, Rose F, Schlaghecke R. Chronic intestinal giardiasis with isolated levothyroxine malabsorption as reason for severe hypothyroidism - implications for localization of thyroid hormone absorption in the gut. Exp Clin Endocrinol Diabetes. 1996;104(2):180-2.

40. Muñoz-Torres M, Varsavsky M, Alonso G. Lactose intolerance revealed by severe resistance to treatment with levothyroxine. Thyroid. 2006;16(11):1171-3. 
41. Pantos C, Mourouzis I, Xinaris C, Cokkinos DV. Thyroid hormone and myocardial ischaemia. J Steroid Biochem Mol Biol. 2008;109(3-5):314-22.

42. Moruzzi P, Doria E, Agostoni PG. Medium-term effectiveness of L-thyroxine treatment in idiopathic dilated cardiomyopathy. Am J Med. 1996;101(5):461-7.

43. Goarin JP, Cohen S, Riou B, Jacquens Y, Guesde R, Le Bret F, et al. The effects of triiodothyronine on hemodynamic status and cardiac function in potential heart donors. Anesth Analg. 1996;83(1):41-7.

44. Cooper DK, Novitzky D, Wicomb WN, Basker M, Rosendale JD, Myron Kauffman $\mathrm{H}$. A review of studies relating to thyroid hormone therapy in brain-dead organ donors. Front Biosci. 2009;14:3750-70.

45. Mullis-Jansson SL, Argenziano M, Corwin S, Homma S, Weinberg $A D$, Williams $M$, et al. A randomized double-blind study of the effect of triiodothyronine on cardiac function and morbidity after coronary bypass surgery. JThorac Cardiovasc Surg. 1999;117(6):1128-34.

46. Novitzky D, Cooper DK, Swanepoel A. Inotropic effect of triiodothyronine (T3) in low cardiac output following cardioplegic arrest and cardiopulmonary bypass: an initial experience in patients undergoing open heart surgery. Eur J Cardiothorac Surg. 1989;3(2):140-5.

47. Henderson KK, Danzi S, Paul JT, Leya G, Klein I, Samarel AM. Physiological replacement of T3 improves left ventricular function in an animal model of myocardial infarction-induced congestive heart failure. Circ Heart Fail. 2009;2(3):243-52.

48. Brent GA, Hershman JM. Thyroxine therapy in patients with severe nonthyroidal illnesses and low serum thyroxine concentration. J Clin Endocrinol Metab. 1986;63(1):1-8.
49. Sandek A, Rauchhaus M, Anker SD, von Haehling S. The emerging role of the gut in chronic heart failure. Curr Opin Clin Nutr Metab Care. 2008;11(5):632-9.

50. Benvenga S, Bartolone L, Pappalardo MA, Russo A, Lapa D, Giorgianni $G$, et al. Altered intestinal absorption of L-thyroxine caused by coffee. Thyroid. 2008;18(3):293-301.

51. Chiu AC, Sherman SI. Effects of pharmacological fiber supplements on levothyroxine absorption. Thyroid. 1998;8(8):667-71.

52. Lilja JJ, Laitinen K, Neuvonen PJ. Effects of grapefruit juice on the absorption of levothyroxine. Br J Clin Pharmacol. 2005;60(3):337-41.

53. Eskes SA, Wiersinga WM. Amiodarone and thyroid. Best Pract Res Clin Endocrinol Metab. 2009;23(6):735-51.

54. Cohen-Lehman J, Dahl P, Danzi S, Klein I. Effects of amiodarone therapy on thyroid function. Nat Rev Endocrinol. 2010;6(1):34-41.

55. Silva JR, Guariento ME, Fernandes GA, Maciel RMB, Ward LS. Impact of long-term administration of amiodarone on the thyroid function of Chagas' disease patients. Thyroid. 2004;14(5):373-9.

56. Cappelli C, Rotondi M, Pirola I, Agosti B, Gandossi E, Valentini U, et al. TSH-lowering effect of metformin in type 2 diabetic patients: differences between euthyroid, untreated hypothyroid, and euthyroid on L-T4 therapy patients. Diabetes Care. 2009;32(9):1589-90.

57. Patrick L. Thyroid disruption: mechanism and clinical implications in human health. Altern Med Rev. 2009;14(4):326-46.

58. Uzma N, Salar BM, Kumar BS, Aziz N, David MA, Reddy VD. Impact of organic solvents and environmental pollutants on the physiological function in petrol filling workers. Int J Environ Res Public Health. 2008;5(3):139-46. 